\title{
Based on Environmental Education: The Effects of Environmental Knowledge and Awareness on the Purchase Intention of New Energy Vehicles in the Southern part of China
}

\author{
Ngqabutho Moyo \\ School of Business: Department of Management Science and Engineering \\ Jiangsu Normal University, 101 Shanghai Road, \\ Tongshan New District, Xuzhou, Jiangsu, China. \\ Faith Masuku \\ School of Business: Department of Management Science and Engineering \\ Shenyang Jianzhu University, 9 Hunnan East Road, \\ Hunnan New District, Shenyang, Liaoning, China.
}

\begin{abstract}
The main objective of this study was to examine the effects of environmental knowledge and awareness on the purchase intention of NEVs, particularly in the southern part of China. In addition to that, this research was also aimed at reflecting the pivotal role played by environmental education in the acquisition of environmental knowledge and awareness. Moreover, this study was also seeking to unearth the influential role of perceived benefits and perceived risks in the purchase decision of NEVs. Stratified random sampling was used as a sampling technique for a targeted sample of participants living in Guangzhou and Shenzhen. This research made use of a qualitative approach to elicit data from the targeted respondents. The outcome of this research shows that environmental knowledge and awareness play a significant role in the purchase intention of NEVs. This research indicates that consumers who are fully equipped with the general knowledge and awareness of their environment are more willing to purchase NEVs, however they also consider other factors such as perceived risks and perceived benefits of NEVs. The goal of environmental education is to impart societal members with the general knowledge and awareness of their environment. This is meant to reinforce sustainable human behaviours and encourage green purchase behaviour. The government of China should therefore continue to improve its environmental education system in order to ensure that it addresses the current issues and adapts to the international standards. In addition, it is also recommended that the perceived risks of NEVs such as; vehicle performance, maintenance costs, possible top speed, driving range, and vehicle safety among others, are addressed in order to enhance the attractiveness of NEVs.
\end{abstract}

Keywords: environmental education; environmental knowledge; environmental awareness; purchase intention; new energy vehicles

\section{INTRODUCTION}

Environmental knowledge and awareness have become dominant in the fields of business and academia due to an increasing concern over environmental pollution and degradation. The most common types of environmental catastrophes which are prevailing at the moment include; climate change, harmful waste secretions, ecosystem breakdown and environmental pollution [Mei et al, 27], and acid rain [Mohiuddin et al, 30]. According to Cetin and Nisanci [4], environmental pollution is one of the most serious problems of the $21^{\text {st }}$ century and it is 
attributed to the overwhelming rate of technological advancements and industrialization, which have led to negligence, insensitive behaviour and destruction of environmental balance.

In many developing countries, environmental pollution is highly caused by excessive carbon dioxide emissions. Mohiuddin et al [30] articulates that environmental pollution is occurring as a result of the motorized vehicles that emit excessive volumes of unhealthy emissions such as carbon dioxide. Transport industry is ranked second in the whole world in terms of carbon dioxide emissions, after electric power [IEA World Energy Outlook, 15]. This has attracted the attention of governments, societies and business organizations throughout the whole world. Due to its economic growth and expansion which encouraged an increase in vehicle ownership among its citizens, China is experiencing an accelerating rate of air pollution [Tianwen, 43]. According to Moyo [32], most citizens of China are using vehicles which rely on conventional diesel and petrol combustion engine, and these types of vehicles are highly responsible for excessive carbon dioxide emissions and air pollution.

In conjunction with the above analysis, Moyo [32] expressed the view that the transportation industry of China is the major source of air pollution. In conjunction with this view, Lou et al [24] indicates that the haze particles contained in the area of Beijing consists of $22.2 \%$ vehicle emissions, $16.7 \%$ coal, $16.3 \%$ dust and $15.7 \%$ industry emissions. The awakening and disturbing fact is that air pollution is becoming a serious threat even to the general public health and the environment at large. Air pollution is now causing low infant weight, premature deaths and increased respiratory symptoms, cancer and dyspnea [Xu et al, 48]. As such, many people and different organizations are developing a deeper concern over their environment and they are advocating for measures that seek to mitigate its problems and ensure its conservation and protection. Mohiuddin et al [30] argues that people's consciousness on environmental issues and green consumption has been highly impacted by the increasing rate of environmental problems and all the consequences involved.

Moyo [32] believes that the only potential solution to environmental problems such as air pollution is the full adoption of green vehicles, and this is because these types of vehicles are not depending on oil and they produce zero direct carbon dioxide emissions. For Mohiuddin et al [30], green vehicles include hybrid cars, electric cars and all cars that rely on alternative fuels. Green vehicles or New Energy Vehicles (NEVs) are all part of environment-friendly automobiles. The adoption of NEVs in China is one of the major developments that have been implemented to address the problem of carbon dioxide emissions. This development is considered as an ideal technological invention that seeks to ensure environmental sustainability [Rezvani et al, 36; Du and Ouyang, 8].

According to Lou et al [24], through drafting supportive policies and attaching incentives such as subsidies which are activated during the sale of electric vehicles, the government of China has created a unique platform that encourages the full adoption of NEVs. This will go a long way in addressing the issue of air pollution. Based on data from the China Association of Automobile Manufacturers (CAAM) [6], in the month of April 2018, the production and sales of NEVs reached 81 thousand units and 82 thousand units respectively, increasing $117.7 \%$ and $138.4 \%$ year on year. For the first four months of the year 2018, the production and sales of NEVs in China had reached 232 thousand units and 225 thousand units respectively, increasing $142.4 \%$ and $149.2 \%$ year on year [CAAM, 6]. As such, Moyo [32:298] argues that "the development and expansion of NEVs in China cannot be underestimated."

It is therefore important for researchers to examine the purchasing behaviour of NEVs in order to encourage their full adoption. Many researchers such as Moyo 32; Rezvani et al, 36; Lou et al 
24; and Zhang et al 51, have conducted research on the purchase intention of environment friendly automobiles. However, although such research has been done, little or no attention has been directed towards examining the direct effects of environmental knowledge and awareness on the purchase intention of NEVs, particularly in the southern part of China. Therefore, this research was aimed at bridging this gap through determining the direct effects of environmental knowledge and awareness on the purchase intention of NEVs. A strong recognition and acknowledgement of the role played by environmental education in the acquisition of environmental knowledge and awareness was made. In addition to that, researchers wanted to unearth the role played by perceived benefits and perceived value of purchasing NEVs. This research adopted a qualitative approach and it made use of interviews and questionnaires to elicit data from the respondents.

\section{Environmental Education and its significance}

According to Gough [13], environmental education can be contextualised as a process of creating an environmentally literate, dedicated and competent citizenry which actively seeks to resolve values conflicts in the man-environment relationship, in a way that is humanistically and ecologically sound in order to arrive at the desired goal of homeostasis between quality of environment and quality of life. The goals of environmental education are aimed at ensuring environmental protection and sustainability, and some of those goals include creating new patterns of behaviour among individuals, groups and the whole society towards the environment, and to provide every societal member with opportunities to obtain knowledge, attitudes, values, commitment and skills required for safeguarding and improving environmental sustainability [UNESCO, 46]. As it seeks to achieve these primary essential goals, environmental education is thus playing the role of imparting and cultivating proenvironmental behaviours among societal members. Echoing this analysis, Keene and Blumstein [17] articulates that environmental education enables individuals, groups and all the societal members to execute sustainable environmental behaviours which seek to conserve the environment. In addition, they state that another key fundamental role of environmental education is to teach people to both respect nature and behave in a manner that will ultimately preserve it. In an attempt to express the role of environmental education, the Millennium Ecosystem Assessment (MEA) [28] entails that environmental education teaches people to consume less, reduce carbon footprint and make appropriate decisions that result in the protection of ecosystems, biodiversity and the future wellbeing of the societal members.

According to Keene and Blumstein [17], many people and different environmental organizations are sharing the same goal of ensuring environmental conservation and protection, and in this regard, environmental education is being regarded as the most significant investment approach towards achieving this goal. Echoing this view, Liu and Guo [23] postulate that environmental education has become the most reliable and significant route being taken towards developing the human's environmental knowledge, as well as proffering solutions to environmental problems. In other words, environmental knowledge is basically reinforced by environmental education.

In conjunction with the above analysis, Keene and Blumstein [17] suggest that environmental education should seek to transform human behaviours now, and empower future generations with adequate environmental knowledge and understanding, as well as offer tools necessary for dealing with environmental problems.

\section{Environmental Knowledge and its effects on the Purchase Intention}

According to Fryxell and Lo [11:45], environmental knowledge is "a general knowledge of facts, concepts and relationships concerning the natural environment and its major ecosystem". In 
this context, environmental knowledge is a key factor in safeguarding environmental sustainability, and without it there will be no chance to behave and act in an environmentally friendly manner [Latif et al, 21]. Environmental knowledge is further recognized and described as a precondition as well as a determinant of environmental attitude [Yusof et al, 50].

The importance of environmental knowledge in cultivating pro-environmental and green purchase behaviour cannot be generalized. Saripah et al [37] are of the view that environmental knowledge should be imparted through environmental education, which in turn should be embedded in the school syllabuses, from as early as pre-school level as a way of cultivating and spreading a culture of environmental values and environmental well-being among citizens. Adding flavor to their analysis, they further stated that environmental knowledge would encourage residents to behave pro-environmentally. Kollmuss and Agyeman [18] define pro-environmental behaviour as behaviour that seeks to consciously minimize the negative effects of an individual's action towards the environment. Pro-environmental behaviour also includes actions taken to minimize one's ecological footprint [Saripah et al, 37] According to Saripah et al [37], although it would not be easy for every individual to directly measure their ecological footprint, it is however assumed that adopting an alternative mode of transport is directly linked to one's ecological footprint.

Yusof et al [50] argues that the role of knowledge has rarely been examined by researchers and linked specifically to the environmental issue, yet it has been an important ingredient over the past few years in determining consumer behaviour. Based on the study about consumer behaviour, environmental knowledge of consumers has positive effects on their purchase intention of green products [Yusof et al, 50]. As such, there is a strong relationship between environmental knowledge and the purchase intention of environment-friendly automobile.

\section{Environmental Awareness and its effects on the Purchase Intention}

Environmental awareness has been an important topic in discussion in past years. It is spontaneously clear to many people however, it is safe to state that there is not a single generally accepted definition of it. Environmental awareness refers to eco-knowledge and concern that residents have towards their environment [Neizari et al, 33]. According to Ma et al [25] environmental awareness include attitude, concern and knowledge about the environment. There are two reasons established by Thompson and Barton [44] as to why people are so much concerned about the environment, and these are; their own sake and this is associated with intrinsic value, and that the nature should be protected for its significance in improving human life.

There is a significant link between consumer knowledge and their purchase behaviours. In this case, consumer knowledge and awareness on how certain products affect the surrounding environment influence intentions to purchase green products [Dehghanan et al, 7]. In the early 1960s, environmental concern was more focused on becoming greener and reducing air pollution. However, since the 1990s, it went beyond air pollution and recycling, and is now more directed to purchase behavior and intentions. Developed countries, such as the USA as well as Asian countries, like Japan, realized the significance of the environment in terms of the consumer purchase intention, especially focusing on green products [Chahal et al., 5].

Environmental pollution in China is to a greater extent attributed to motorized vehicles that produce large volumes of unhealthy emissions like carbon dioxide [Mohiuddin et al, 30]. It also poses a threat to public health and air pollution is very intense in most urban cities [Xu et al, 48]. Research has confirmed that education and awareness are one of the most effective ways to ultimately mitigate and slow environmental degradation. 
The transition from gas to electric vehicles can help reduce gas emissions and air pollution however; several studies have shown that there is general lack of knowledge and awareness on electric vehicles. Kurani et al [19] states that vehicle users who have been exposed to energy vehicles are most likely to value them more highly and consider them a better choice in the future as these energy vehicles would enhance the quality of the air and also reduce unhealthy emissions. Most automobile companies have since directed their resources on saving the environment through the production of energy vehicles that produce less toxic emissions.

\section{Perceived Benefits of NEVs}

According to Forsythe et al, [10], perceived benefits can be defined as the advantages derived from the adoption or purchase of a product. According to a research which was carried out by Moyo [32], many consumers are interested in purchasing electrical vehicles because of the fact that they do not emit excessive carbon dioxide, which is very harmful to the environment. Such consumers are fully equipped with environmental knowledge and awareness, and this type of knowledge and awareness can only be acquired through environmental education. One can therefore acknowledge the view that environmental education imparts environmental knowledge and awareness to the societal members, and thereby enabling them to exert proenvironmental or sustainable behaviours such as green consumption.

Moreover, some consumers are motivated to purchase electrical vehicles because of their low cost [Liu and Santos, 22]. In China, electrical vehicles are very affordable because of the government incentives which are meant to encourage their full adoption [Moyo, 32]. According to Berensteanuand and Li [2] and Gallagher and Muehlegger [12], government incentives such as subsidies play a pivotal influential role in the purchase decision. In addition to the role played by the existence of environmental knowledge and awareness in encouraging the purchase of green vehicles, the above discussed range of benefits also motivates consumers to choose electrical vehicles over vehicles that rely on conventional diesel and petrol combustion engine.

\section{Perceived Risks of NEVs}

According to Shimp and Bearden [39], perceived risk can be defined as the perception of the uncertainty and unexpected results of purchasing a given product or service. Consumers would not want to buy something that does not meet their standards or that may not meet their satisfaction levels, hence they would rather avoid the mistake of making the final purchasing decision. Hence perceived risk plays a significant influential role in the purchase decision. When it comes to NEVs, electric vehicles in particular, many consumers are discouraged to purchase these types of vehicles because of factors such as battery life, battery capacity, battery stations and charging time [Liu and Santos, 22]; Carley et al, [3]. According to Jensen et al [16], when thinking of buying an electric vehicle, consumers also consider other factors such as driving range, possible top speed, appearance, vehicle performance, maintenance costs, and vehicle safety. In this regard, it should be noted and acknowledged that although consumers would be fully equipped with enough knowledge and awareness about their environment and all the problems affiliated, the above highlighted factors or perceived risks may have a negative impact on the final purchase decision of NEVs.

\section{Purchase Intention in relation to Environmental Knowledge and Awareness}

According to Schiffman and Kanuk [38] purchase intention is the possibility of a consumer to buy a certain product. Purchase intention for environmentally friendly commodities is defined by Nik Abdul Rashid (2009) as the willingness and readiness to buy eco-friendly products. Afroz et al [1] indicated that there are a number of factors which influence consumer purchase intention of electric vehicles which include but not limited to capacity and durability of the 
battery life, price and range. Monroe [31] depicts that consumer purchase intentions are largely driven by perceived value of a product which is as a result of the expected quality of that particular product. In their study, Gallagher and Muehlegger [12] found out that people with strong preferences for environmentalism prefer energy vehicles. Personal concern for the environment [Lai et al, 20] and individual responsibility to make a difference also motivates environmental conscious behaviours [Ellen et al, 9].

Yusof et al [50] believes that consumers who are concerned and well informed about their environment are more willing to purchase environmentally friendly products. It can therefore be acknowledged that environmental knowledge and awareness imparts a pro-environmental or sustainable behaviour on consumers and as a result, such consumers are highly motivated to purchase green products such as NEVs. According to Ziegler [52], when thinking about buying a vehicle, consumers who are environmentally concerned would take into consideration factors such as carbon dioxide emissions and its negative effects to the environment, and the general public health.

\section{THEORITICAL FRAMEWORK}

This research was guided by a model called the Stimulus-Organism-Response (SOR) model, which was crafted by Mehrabian and Russel in 1974. According to this model, the stimulus from the environment affects a person's cognitive and reactions and it in turn leads to a specific behaviour [Mehrabian and Russel, 29]. In other words, the Stimulus (S) has an effect on Organism (O), which in turn result in a Response (R) [Mehrabian and Russel, 29].This is echoed by Turley and Milliman [45], as they articulate that a stimulus involves a set of variables and behavioral responses. In this research, Stimulus covers a set of variables such as environmental education, environmental knowledge and environmental awareness, which affects a Response, that is, purchase intention of NEVs, as mediated or with a strong consideration of Organism, that is; the direct effects of perceived benefits and perceived risk of purchasing NEVs.

To shed more light, the key objective of environmental education is to ensure that the societal members are fully equipped with adequate knowledge and awareness of their environment, its problems and the possible solutions that can be adopted to ensure environmental sustainability. It is this type knowledge and awareness that motivates consumers to purchase NEVs as a way of protecting their environment from potential catastrophes such as air pollution and global warming. The adoption of NEVs is acknowledged as one of the major developments in ensuring environmental sustainability. Mohiuddin et al [30] clearly state that the younger generation should be fully imparted with environmental knowledge and awareness since they are ultimately in charge of the planet's survival. Therefore, the acquisition of environmental knowledge plays a significant role in ensuring environmental conservation, preservation and sustainability. However, based on this model, the final purchase decision is also dependent on the consideration of other factors such as perceived benefits such as low cost and affordability of NEVs, and perceived risks such as vehicle performance, maintenance costs, possible top speed, driving range, and vehicle safety.

\section{METHODOLOGY}

According to Wellington and Szcerbinnski [47], methodology is the activity of selecting, reflecting upon, evaluating and justifying the methods used on a particular research. This research took a qualitative approach which is naturalistic and is aimed at gaining insight, investigating and understanding particular issues [Stokes, 42]. Stratified random sampling was used as it gives everyone in the subgroups a chance to be selected [Singleton and Straits, 40]. 
Primary data was gathered through interviews and questionnaires from 220 respondents residing in Guangzhou and Shenzhen.

\section{FINDINGS AND DISCUSSIONS}

Fig. 1: Demographic Data

\begin{tabular}{|c|c|c|c|c|c|c|c|c|c|c|}
\hline \multirow[b]{2}{*}{ City } & \multicolumn{2}{|c|}{ Gender } & \multicolumn{4}{|c|}{ Employment Status } & \multicolumn{4}{|c|}{ Age Range } \\
\hline & $\mathbf{M}$ & $\mathbf{F}$ & Employed & $\begin{array}{l}\text { Self- } \\
\text { Employed }\end{array}$ & Unemployed & Student & $\begin{array}{l}20- \\
30\end{array}$ & $\begin{array}{l}31- \\
40\end{array}$ & $\begin{array}{l}41- \\
50\end{array}$ & $\begin{array}{l}50 \\
+\end{array}$ \\
\hline Guangzhou & 62 & 58 & 16 & 50 & 11 & 21 & 40 & 34 & 23 & 12 \\
\hline Shenzhen & 53 & 47 & 41 & 18 & 20 & 43 & 41 & 24 & 15 & 31 \\
\hline Total & 115 & 105 & 57 & 68 & 31 & 64 & 81 & 58 & 38 & 43 \\
\hline Grand Total & \multicolumn{2}{|c|}{220} & \multicolumn{4}{|c|}{220} & \multicolumn{4}{|c|}{220} \\
\hline
\end{tabular}

Initially the research targeted 230 respondents, however; six of them were not able to avail themselves for the interviews due to their busy schedules. Three respondents failed to respond to the questionnaire, thus returned them unanswered whilst one respondent did not return the questionnaire apologetically stating that he misplaced it. Out of the 220 respondents who participated in this research, 55\% were male thus 120 participants and the remaining 100 were females (45\%), and this is quite reasonable since the males outnumber the females in China [Statista, 41]. The majority of the respondents from Guangzhou were self-employed and this is because this city is one of the cities which are regarded as the key economic hub of China [OECD Economic Surveys China, 35]. Of the 100 participants from Shenzhen, 43 were students, 41 were formally employed and 31 were unemployed and dependent on their families. The majority of the respondents were young citizens ranging from 20 to 40 years and most of them want the best for their environment as a way of enhancing their life expectancy.

\section{Environmental Education and its significance}

All respondents were very much aware of, and highly concerned about their environment and its problems. As they were asked to express their views concerning the meaning of environmental education, one of the respondents from the city of Guangzhou indicated that "environmental education is concerned with the acquisition of environmental knowledge and awareness, and the cultivation of sustainable human behaviours." This was echoed by another respondent from the city of Shenzhen who expressed that "the goal of environmental education is to impart societal members with the general knowledge and awareness of their environment as a way of helping them to adopt and execute a pro-environmental and sustainable human behaviour." Environmental education can thus be contextualised as the acquisition of the general knowledge and awareness about the environment, its problems, as well as possible solutions. This is echoed by McBeath et al [26:33] as they articulate that "environmental education refers to the way people in every walk of life think about, judge and select the lifestyles and livelihoods that will reduce or solve environmental problems and help them effectively adapt to their natural and social environment."

All respondents indicated that they are pleased to have had the opportunity to acquire environmental knowledge and awareness during their primary and middle school education. As such, this is providing a clear cut that the government of China is indeed highly committed to ensuring the protection of its environment through its education system. This is backed by McBeath et al [26] as they depict that in China, environmental problems are indeed increasingly attracting the global attention, but however critics often overlook the sizable efforts made by the Chinese citizens and their government to change attitude and behaviour of every Chinese citizen in order to improve environmental outcomes. 
The government of China has indeed made major commitments in developing and strengthening its environmental education system. According to McBeath et al [26], since 1986 China has managed to implement a nine year compulsory education system which includes six years of primary and three years of middle school education, and this education system include the teaching of environmental education. Eighteen respondents from the city of Shenzhen expressed that during their middle school education they were also taught about environmental catastrophes such as air pollution, including its causes, problems and potential solutions. One of the respondents expressed that "air pollution is highly caused by excessive carbon dioxide emissions." This is supported by Moyo [32] as he propounded the view that air pollution is highly triggered by excessive volumes of carbon dioxide emissions emanating from the transportation industry.

One of the respondents from the city of Guangzhou pointed out that "carbon dioxide emissions should be monitored at all costs because of the nature of their dangerous effects to the environment and the general public health." Another respondent reiterated that "through environmental education, I got to learn about environmental catastrophes such as climate change, global warming and environmental pollution." In addition to that, the same respondent suggested that people should advocate for green consumption as a way of ensuring environmental sustainability. In the same vein, Moyo [32] articulates that the adoption of green vehicles is one of the effective solutions to the environmental problems. Hence environmental education encourages people to develop a sensitive behaviour towards their environment.

\section{Environmental Knowledge and its effects on the Purchase Intention}

All respondents appreciated the role of environmental education in equipping societal members with the general knowledge concerning their environment and how to conserve and protect it. Asked to express their views about the meaning of environmental knowledge, one of the respondents from the city of Guangzhou mentioned that "environmental knowledge refers to the general knowledge about the environment at large, its problems and possible solutions." In the same context, another respondent from the city of Shenzhen entailed that "environmental knowledge refers to the general facts about the environment." Sharing the same sentiment, Yusof et al [50] defined environmental knowledge as the understanding that residents have about their environment. Hence environmental knowledge refers to any given knowledge about the environment at large.

One of the environmentally concerned respondents expounded on the view that "environmental knowledge encourages residents to act in an environmentally friendly manner in their day-to-day lives." Another respondent from the city of Shenzhen expressed that environmental knowledge encourages residents to adopt a pro-environmental behaviour such as purchasing environment-friendly automobile. A research which was carried out by Moyo [32] indicated that people who are concerned about their environment often choose to consume environment-friendly products as a way of ensuring the sustainability of their environment. This simply reflects the fact that the general knowledge that people acquire concerning their environment encourages them to purchase green products such as NEVs.

Due to the mandatory nature of the education system of China, which covers environmental education in both primary and middle school levels, all Chinese citizens are in a better position to understand their environment, its problems such as air pollution, and all the potential solutions, for example; the adoption of NEVs and the general consumption of environmentfriendly products. All respondents were indeed aware of environmental issues, and they condemned the existence of air pollution in their cities, citing its negative effects to the general 
public health, for instance they said that it causes lung diseases and low infant weight. This is supported by Yucel and Ozkan [49] as they clearly state that air pollution causes respiratory problems, cancer and dyspnea. Given these challenges, all respondents applauded the idea of fully adopting NEVs. The full adoption of NEVs in China will go an extra mile in reducing carbon dioxide emissions and protecting the environment.

\section{Environmental Awareness and its effects on the Purchase Intention}

In an attempt to define environmental awareness, one of the respondents pointed out that "environmental awareness is associated with the awareness of the general facts concerning our environment." Another responded highlighted that "environmental awareness is the manner in which a person behaves towards the environment." The same respondent went on to explain that unhealthy air is dangerous for our lungs; hence "we ought to prevent or at least try to reduce it." Another respondent strongly expressed that "environmentally concerned citizens should be more than willing to purchase environmentally friendly products which will not harm their environment. This will reduce environmental catastrophes such as air pollution." Moyo [32] reinforced this stating that environmentally concerned people ought to ensure that their environment is preserved and sustained.

In the same vein, another respondent articulated that "a lot of toxic emissions come from the transportation industry, and such emissions are contributing vastly to air pollution. It is therefore our duty as residents of Guangzhou to be highly conscious and be willing to attempt to buy environment-friendly automobiles." In their findings, Hai and Mai [14] indicated that consumers with more concern about ecological matters take it upon themselves to practice green purchasing. In other words, environmental awareness reinforces pro-environmental or sustainable human behaviours among societal members. All the respondents highly appreciated the idea of the full adoption of NEVs. They applauded the government of China for continuously improving the nation's environmental education system.

\section{Perceived Benefits of NEVs}

All respondents applauded the idea of fully adopting environment-friendly automobiles such as electric vehicles due to a number of benefits. Three quotas of respondents found reduced or zero carbon dioxide emissions as the most attractive benefit of purchasing NEVs. One of the respondents from the city of Shenzhen expressed that "NEVs should be fully embraced due to their significant contribution to environmental protection and conservation." This was acknowledged by another respondent from the city of Guangzhou who reiterated that "as an environmentally concerned citizen of China, I opted to purchase an electric vehicle because it produces zero carbon dioxide emissions." As such, the technology of electric vehicles that allows them to produce zero carbon dioxide emissions enhances their attractiveness; hence it affects the purchase intention of electric vehicles in a positive way.

One of the respondents from the city of Shenzhen went further and stated that "the most attractive thing about NEVs, especially electric vehicles is that they are cheap and as such, they are affordable." This was echoed by another respondent who pointed out that "in China, electric vehicles are very affordable due to government incentives such as subsidies that are attached during their sale." Hence cost is one of the key factors that affect the purchase decision of NEVs. The government of China has indeed gone an extra mile in promoting the adoption of electric vehicles. During the sale of all hybrid and electric vehicles, the government of China is issuing incentives that lower the price of these types of vehicles [Lou et al, 24]. In China, NEVs are thus affordable, and this implies that every citizen is highly challenged and motivated to opt for these types of vehicles instead of the ones that rely on conventional diesel and or petrol combustion engine. 


\section{Perceived Risks of NEVs}

Having enough knowledge and awareness about the environment does not guarantee the purchasing of, and full adoption of NEVs, especially electric vehicles. This was unearthed by this research, in which case one hundred and ninety seven respondents expressed dissatisfaction on some of the features of these types of vehicles. Asked to express what they think could be the potential risks of purchasing an electric vehicle, one of the respondents from the city of Shenzhen stated that "I am very skeptical about their battery capacity and life." In addition to that, the same respondent indicated that "I also think that the charging time can be really frustrating as it may be associated with delays. I don't think I would therefore buy an electric vehicle anytime soon" Indeed, when it comes to electric vehicles, many consumers tend to be worried about factors such as charging time, battery stations, battery capacity and battery life [Jensen et al, 16].

Eleven more respondents from the city of Guangzhou expressed their dissatisfaction about electric vehicles based on factors such as possible top speed, driving range, vehicle performance, vehicle safety, and maintenance costs. According to Zhang et al [51], these factors have a strong effect on the purchase decision of NEVs. These respondents expressed that they were of course worried about the increasing rate of carbon dioxide emissions, especially from the transportation sector, but however they would not risk spending money on vehicles that would not meet their expectations and satisfaction levels. Hence this study is also submitting that perceived risks of NEVs also affects the purchase decision of these types of vehicles.

\section{Purchase Intention in relation to Environmental Knowledge and Awareness}

In a focus group interview, eleven of the respondents concurred that human beings ought to adopt green purchase behaviour habits to ensure safer surroundings. This was supported by a participant who highlighted that "not only should the land be kept clean but the air too. Diesel and petrol engines emit a lot of carbon dioxide which pollute the air. I would therefore say electric cars are better." In his findings, Moyo [32] indicated that individuals who are concerned about the environment prefer to purchase NEVs as a way of reducing air pollution. According to a student participant from Shenzhen "the lack of adequate environmental knowledge should be addressed by the authorities." Three more respondents agreed that not everyone is well educated, if more information was made available to the public, more people would be willing to purchase NEVs such as electric cars since they do not produce any toxic gases.

Lack of adequate knowledge and awareness on environmental issues are some of the reasons why some of the residents are having challenges in adopting and executing green purchase behaviours. This was supported by another respondent who stated that "the government of China should promote environmental awareness workshops as way of educating its people on how to preserve the environment and minimize catastrophes such as air pollution." As such, it can be acknowledged that environmental knowledge and awareness motivates consumers to make better informed decisions when it comes to their choice of vehicles. Another responded indicated that, "as an environmentally concerned citizen, I am willing to buy an environmentally friendly automobile, an electric car to be specific; but however I am worried about other factors such as their possible top speed, driving range, performance, maintenance costs, and safety." Given this response, it can also be acknowledged that perceived risks of NEVs also affect the purchase intention of NEVs.

\section{CONTRIBUTION TO NEW KNOWLEDGE}

This study is contributing immensely to the body of new knowledge, especially in the field of consumer behaviour and environmental sustainability. It managed to examine the direct effects of environmental knowledge and awareness on the purchase intention of NEVs, 
particularly in the southern part of China. In addition to that, the exceptionality part of this study is centered on the fact that it managed to appreciate the significant role played by environmental education in the acquisition of environmental knowledge and awareness, particularly in the education system of China. Moreover, this study also unearthed the influential role played by the perceived benefits and perceived risks in the purchase decision of NEVs. In other words, such an approach has never been adopted before, especially in the field of consumer behaviour, environmental sustainability and in the context of Southern China. Hence future researchers shall be able to utilize this distinctive nature and approach of this research to advance future research.

\section{CONCLUSION}

The key objective of this study was to examine the effects of environmental knowledge and awareness on the purchase intention of NEVs, particularly in the southern part of China. In addition to that, this research was also aimed at reflecting the pivotal role played by environmental education in the acquisition of environmental knowledge and awareness. Moreover, this study was also seeking to unearth the influential role of perceived benefits and perceived risks in the purchase decision of NEVs. Stratified random sampling was used as a sampling technique for a sample of participants living in Guangzhou and Shenzhen. The study made use of a qualitative approach to elicit data from the targeted respondents. The outcome of this research shows that environmental knowledge and awareness play a significant role in the purchase intention of NEVs. According to this research, environmental knowledge and awareness encourages consumers to adopt and exert a pro-environmental and sustainable human behaviour in their day-to-day lives. Through environmental knowledge and awareness, residents get enlightened about the general facts concerning their environment, its problems and the possible solutions. The findings of this research indicates that consumers who are fully equipped with the knowledge and awareness of their environment are more willing to purchase NEVs, but however they also take into consideration, other factors such as perceived risks and perceived benefits of NEVs. Perceived benefits of NEVs enhance the attractiveness of NEVs and as such, they are having a positive effect on the purchase intention. However perceived risks of NEVs on the other side, are negatively affecting the purchase intention of NEVs. Based on the findings of this study, the goal of environmental education is to impart societal members with the general knowledge and awareness of their environment. This type of knowledge and awareness will help societal members to adopt and execute proenvironmental and sustainable human behaviours such as adopting NEVs. The government of China should therefore continue to improve its environmental education system in order to ensure that it addresses the current issues. In addition, it is also recommended that the perceived risks of NEVs such as vehicle performance, maintenance costs, possible top speed, driving range, and vehicle safety among others, are addressed and improved in order to enhance the attractiveness of NEVs.

\section{References}

Afroz, R., Masud, M., Akhtar, R, Islam, M., and Duasa, J. (2015). Consumer Purchase Intention towards environmentally friendly vehicles: An Empirical investigation in Kuala Lumpur. Environ. Sci. Pollut, 22, 1615316163.

Berensteanuand, A., and Li, S. (2011). Gasoline price, government support and the demand for hybrid vehicles. Int. Econ. Rev, 52, 161-182.

Carley, S., Krause, R. M., Lane, B. W., Graham, J. D. (2013). Intent to purchase a plug-in electric vehicle: A survey of early impressions in large US cities. Transp. Res, 18, 39-45.

Cetin, G., and Nisanci, S. H. (2010). Enhancing students' environmental awareness. Procedia Social and Behavioral Sciences 2, 1830-1834. 
Chahal, H., Dangwal, R., \& Raina, S. (2014). Antecedents and consequences of strategic green marketing orientation. Journal of Global Responsibility, 5(2), 338-362.

China Association of Automobile Manufacturers (CAAM) (2018). Automobile Statistics www.caam.org.cn

Dehghanan, H., and Bakhshandeh, G. (2014). The Impact of Green Perceived Value and Green Perceived Risk on Green Purchase Behavior of Iranian Consumers. International Journal of Management and Humanity Sciences, 3(2), 1349-1357.

Du, J., and Ouyang, D. (2016). Progress of Chinese electric vehicles industrialization in 2015: A review. Applied Energy 188, 529-546.

Ellen, P. S., Wiener, J. L., and Cobb-Walgren, C. (1991). The role of perceived consumer effectiveness in motivating conscious behaviours. J Public Policy Mark, 10, 102-117.

Forsythe, S., Liu, C., Shannon, D., and Gardner, L. C. (2006). Development of a scale to measure the perceived benefits and risks of online shopping. Journal of Interactive Marketing, 20 (2) 55-75.

Fryxell, G. E., and Lo, C. W. H. (2003). The influence of environmental knowledge and values on managerial behaviours on behalf of the environment: An empirical examination of managers in China. Journal of Business Ethics, 46, 45-69.

Gallagher, K. S., and Muehlegger, E. (2011). Giving green to get green? Incentives and consumer adoption of hybrid vehicle technology. In Lai, I. K. W., Liu, Y., Sun, X., Zhang, H., and Xu W. (2015). Factors Influencing the Behavioural Intention towards Full Electric Vehicles: An Empirical Study in Macau. Sustainability, 7, 12564-12585.

Gough, A. (1997). Education and the environment: policy, trends and the problems of marginalization. Australian Education Review, 39, Melbourne, Australia: The Australian Council for Educational Research Ltd.

Hai, H. V., and Mai, P. N., (2012). Environmental Awareness and Attitude towards green purchasing of Vietnamese Consumers, VNU- University of Economics and Business.

IEA World Energy Outlook. (2006) International Energy Agency: Paris, France.

Jensen, A. F., Cherchi, E., and Mabit, S.L. (2013). On the stability of preferences and attitudes before and after experiencing an electric vehicle. Transp. Res. D, 25, 24-32.

Keene, M., and Blumstein, D. T. (2010). Environmental education: A time of change, a time for change. Evaluation and Program Planning 33, 201-104.

Kollmuss, A., and Agyeman, J. (2002). Mind the gap: why do people act environmentally and what are the barriers to pro-environmental behaviour? Environmental Education Research, 8(3).

Kurani, K. and Caparello, N. (2016). New Cars buyer's Valuation of zero Emission Vehicles California, Institute of Transportation Studies, University of California, Davis, Research Report UCD- ITS- RR-16-16.

Lai, I. K. W., Liu, Y., Sun, X., Zhang, H., and Xu W. (2015). Factors Influencing the Behavioural Intention towards Full Electric Vehicles: An Empirical Study in Macau. Sustainability, 7, 12564-12585.

Latif, S. A., Omar, M. S., Bidin, Y. H., and Awang, Z. (2013). Analyzing the effect of situational factor on recycling behaviour in determining the quality of life. Journal of Asian Behavioural Studies, 3(8)

Liu, J., and Santos, G. (2015). The plug-in hybrid electric vehicles potential for urban transport in China: The role of energy sources and utility factors. Int. J. Sustain. Transp, 9, 145-157.

Liu, S., and Guo, l. (2018). Based on Environmental Education to Study the Correlation between Environmental Knowledge and Environmental Value. EURASIA Journal of Mathematics, Science and Technology Education, 14(7), 3311-3319.

Lou, Y., Wang, W., and Yang, X. (2017). Customers' attitude on new energy vehicles' policies and policy impact on customers' purchase intention. Energy Procedia 105, 2187-2193.

Ma, G. G. H., Rau, P. L. P., and Guo, Z. (2018). The effects of Environmental Awareness and Consumption Value on Green Makeup Product Purchase Intentions. Psychology, 9, 1898-1916.

McBeath, G., McBeath, J. H., Qing, T., and Yu, H. (2014). Environmental Education in China. Edward Elgar Publishing. DOI:https://doi.org/10.4337/9780857933508.00010.

Mei, N. S., Wai, C., W and Ahamad, R. (2016). Environmental Awareness and Behaviour Index for Malaysia. Procedia - Social and Behavioral Sciences 222, 668-675. 
Moyo, N., \& Masuku, F. (2018). Based on Environmental Education: The Effects of Environmental Knowledge and Awareness on the Purchase Intention of New Energy Vehicles in the Southern part of China. Advances in Social Sciences Research Journal, 5(11) $390-402$.

MEA, U. (2005). Living beyond our means: natural assets and human well-being. Statement from the Board Millennium Ecosystem Assessment BOTME Assessment, in Keene, M., and Blumstein, D. T. (2010). Environmental education: A time of change, a time for change. Evaluation and Program Planning 33, 201-104.

Mehrabian, A., and Russel, J. A. (1974). An approach to environmental psychology. Cambridge, MA:MIT Press.

Mohiuddin, M., Mamun, A. A., Syed, F. A, Masud, M. M., and Su, Z. (2018). Environmental Knowledge, Awareness, and Business School Students' Intentions to Purchase Green Vehicles in Emerging Countries. Sustainability, 10, 1534 .

Monroe, Kent B. (2003). Pricing: Making Profitable Decisions, 3d ed. Burr Ridge, IL: McGraw-Hill/Irwin.

Moyo, N. (2018). Environmental Concern and Purchase Intention of Electric Vehicles in the Eastern part of China. Archives of Business Research, 6(8), 297-309.

Neizari, M. M., Nikundis, L. A., and Samadi, B. (2017). A study on Hybrid Car Purchasing Intention. International Journal of Business and Social Sciences. Volume 8, No 12.

Nik Abdul Rashid, N. R. (2009). Awareness of eco-label in Malaysia's green marketing initiative. International Journal of Business and Management, 4 (8) 132-141.

OECD Economic Surveys China 2017, China. www.oecd.org

Rezvani, Z., Jansson, J., and Bodin, J. (2015). Advances in consumer electric vehicle adoption research: A review and research agenda. Transport Research Part D, 34, 122-136.

Saripah, A. L., Yeop Hussin, B., and Zainudin, A. (2013) Towards the realization of green cities: The moderating role of the residents' education level. Paper presented at ASEAN Conference on Environmental-Behaviour Studies, Hanoi, Vietnam.

Schiffman, L. G., and Kanuk, L. L. (1997). Consumer Behaviour $6^{\text {th }}$ ed. Prentice Hall. London.

Shimp, T. A., and Bearden, W.O. (1982). Warranty and Other Extrinsic Cue Effects on Consumers' Risk Perceiptions. Journal of Consumer Research, 9(1) 38-46.

Singleton, R.A. and Straits, B.C. (1999), Approaches to Social Research 3rd Ed, Oxford University Press Inc: New York.

Statista. (2016). Population in China from 2006 to 2016, by gender (in million inhabitants) www.statista.com

Stokes, J. (2003), How to do media and cultural studies, Sage Publications: London.

Tianwen, L. (2010). Electric Vehicle Industry Overview in China. Battery World, 5(1), 8-9.

Thompson, S. C. G., and Barton, M. A. (1994). Eco-centric and anthropocentric attitudes towards the Environment. Journal of Environmental Psychology, 14, 149-157.

Turley, W. L., and Milliman, R. E. (2000). Atmospheric Effects of Shopping Behavior: A Review of the Experimental Evidence. Journal of Business Research, 49, 193-211.

UNESCO. (1978). Intergovernmental conference on environmental education, Tbilisi (USSR), 14-26 October 1977. Final Report. Paris: UNESCO.

Wellington, J. and Sczerbinsk, M. (2007). Research Methods for the Social Sciences, Cromwell Press: London.

Xu, X., Wang, L., and Niu, T. (2002). Air pollution and its Health Effects in Beijing. Wiley Online Library, Ecosystem Health / Volume 4, Issue 4.

Yucel, E. O., and Ozkan, M. (2016). Determining the perceptions of pre-service science teachers regarding environmental problems through word association. International Journal of Learning and Teaching, 08, 164-173.

Yusof, J. M., Singh, G. K., and Razak, R. A. (2013). Purchase Intention of Environment-Friendly Automobile. Procedia, Social and Behavioural Sciences, 85, 400-410.

Zhang, Q., Ou, X., Yan, X., and Zhang, X. (2017). Electric Vehicle Market Penetration and Impacts on Energy Consumption and CO2 Emission in the Future: Beijing Case. Energies, 10, 228; doi: 10.3390/en10020228.

Ziegler, A. (2012). Individual characteristics and stated preferences for alternative energy sources and propulsion technologies in vehicles: A discrete choice analysis for Germany. Transp. Res, 46, 1372-1385. 